\title{
Volume ou Valor? O Papel do Radiologista na Gestão dos Exames Radiológicos
}

\author{
Volume or Value? The Role of the Radiologist in \\ Managing Radiological Exams
}

\author{
Carlos Francisco SILVA $\triangle^{1}$, Teresa GUERRA ${ }^{1}$ \\ Acta Med Port 2017 Sep;30(9):628-632 - https://doi.org/10.20344/amp.8253
}

\begin{abstract}
RESUMO
Introdução: Pretendeu-se perceber os motivos e quantificar o número de ecografias e tomografias computorizadas que potencialmente são desperdiçadas a nível da urgência hospitalar na nossa instituição, e a importância que o radiologista pode ter na gestão e triagem desses exames.

Material e Métodos: Definiu-se que os exames urgentes pendentes há mais de sete dias seriam objeto de análise quanto ao motivo de não realização, consultando os registos médicos eletrónicos. Foram usadas seis causas para cancelamento dos referidos pedidos: 'Alteração do estado do doente', 'Desistência, recusa ou abandono do doente', 'Falecimento do doente'; 'Sem critério ou contraindicado', 'Falta de recursos humanos' e 'Engano na marcação'.

Resultados: No ano de 2015 obtivemos 1211 exames cancelados, por estarem pendentes há mais de uma semana. As quatro primeiras causas totalizaram 602 exames (somatório de 283, 94, 41 e 184). As duas últimas, 609 (somatório de 29 e 580).

Discussão: Verificou-se que os 602 exames correspondentes ao somatório das quatro primeiras causas refletem um potencial desperdício em exames pois não foram determinantes na abordagem do episódio de Urgência e no destino final do doente. Debaixo desta ponta do iceberg poderão estar ainda mais exames e doentes que não escaparam a exames inadequados ou injustificados.

Conclusão: O radiologista poderá gerir melhor os exames radiológicos requisitados, triando eficazmente, num ambiente de equipa multidisciplinar, promovendo a elaboração e apoiando a aderência a normas de orientação e diminuindo potencialmente as requisições através de pareceres ou segundas opiniões.
\end{abstract}

Palavras-chave: Diagnóstico por Imagem; Procedimentos Desnecessários; Radiologia; Serviço de Urgência

\section{ABSTRACT}

Introduction: The purpose of this study was to understand the reasons and quantify the number of ultrasounds and computed tomographies that are potentially wasted in the hospital emergency in our institution, and the importance that the radiologist can have in the management and screening of these exams.

Material and Methods: It was decided that urgent tests that were pending for more than seven days would be the object of analysis as to why they were not performed, consulting the electronic medical records. Six causes were used to cancel the requests: 'Changing the patient's status', 'Patient's withdrawal, refusal or abandonment', 'Patient's death'; 'No criteria or contraindicated', 'Lack of human resources' and 'Mistaken request'.

Results: In the year 2015 we obtained 1211 canceled exams, since they were pending more than a week ago. The first four causes totaled 602 exams (sum of 283, 94, 41 and 184). The last two, 609 (sum of 29 and 580).

Discussion: It was verified that the 602 exams corresponding to the sum of the first four causes reflected a potential waste in clinical tests since they were not determinant in the approach of the Emergency episode nor on the final destiny of the patient. Under the tip of the iceberg may exist further examinations and patients who have not escaped inadequate or unjustified examinations.

Conclusion: The radiologist can better manage the required radiological examinations, effectively screening within a multidisciplinary team environment, promoting the development and supporting the respect of guidelines, and potentially reducing requests through opinions or second opinions.

Keywords: Diagnostic Imaging; Emergency Service, Hospital; Radiology; Unnecessary Procedures

\section{INTRODUÇÃO}

Um novo paradigma começa a emergir no horizonte da Radiologia. De um modelo que privilegia e remunera um determinado volume de trabalho, na gíria o chamado pagamento à peça, começa a verificar-se uma mudança de rumo para um modelo que põe a tónica no valor do serviço prestado. ${ }^{1}$

Acelerado pela conjuntura económica e financeira a nível global, com maior ênfase no sistema norte-americano, esta mudança teve origem nos custos em saúde determinados pelos exames radiológicos numa espiral sempre ascendente. $^{2}$ Desta forma, uma remuneração ou pagamento de um serviço baseado no valor e não no volume, tenderia a conter mais os custos. As vantagens do modelo baseado no valor adviriam assim da ausência de um conflito de interesses com a realização de exames radiológicos redundantes ou completamente desnecessários, colocando a perspetiva no doente e no episódio de cuidados de saúde, o que se conseguiria através de uma melhor racionalização e gestão dos exames da Radiologia. Estes seriam eficazmente triados em primeira instância pelo médico radiologista, afastando-se assim do modelo de pagamento por serviço ou à peça, em que simplesmente se agenda e executa qualquer exame que seja prescrito pelo clínico requisitante.

O modelo de gestão ao volume teve bastante incremento

1. Serviço de Imagiologia. Centro Hospitalar de Setúbal. Setúbal. Portugal.

$\square$ Autor correspondente: Carlos Francisco Silva. carlos.f.silva@chs.min-saude.pt

Recebido: 28 de setembro de 2016 - Aceite: 03 de maio de 2017| Copyright $\odot$ Ordem dos Médicos 2017 
nos últimos anos, tendo-se assistido ao encerramento de alguns serviços de Radiologia em hospitais portugueses mais pequenos e periféricos, sendo substituídos por empresas especializadas em Telerradiologia. O sentimento geral entre os clínicos foi o de que muitas das vezes a qualidade do serviço prestado foi mediana ou medíocre com muitas falhas, erros, omissões e imprecisões nos relatórios, embora em termos de agendamento e de facilidade de conseguir o exame tenha sido melhorado, especialmente depois do 'fecho da torneira' ocorrido em 2011 ao impossibilitar-se a requisição de exames ao exterior. ${ }^{3}$

Em 2012, a Sociedade Americana de Medicina Interna lançou uma campanha intitulada Choose Wisely em que estabelece recomendações baseadas na evidência em conjunto com mais de 50 sociedades e colégios da especialidade, sendo que $29 \%$ destas recomendações dizem respeito a exames radiológicos ${ }^{4}$ (a maior fatia correspondente a testes e procedimentos diagnósticos). $\mathrm{O}$ intuito desta campanha foi estabelecer uma melhor adequação no pedido de exames analíticos e de imagem com o objetivo de racionalização e de redução de custos, principalmente numa altura em que o sistema norte-americano, muito baseado em seguradoras começa já a estabelecer perfis entre os vários clínicos prescritores, analisando assim aqueles que maiores taxas de exames negativos ou redundantes prescrevem, deixando de reembolsar os piores. ${ }^{5,6}$ Esta linha de orientação segue em consonância com os modelos já existentes ${ }^{7}$ a nível da Medicina Geral e Familiar em Portugal, nomeadamente as unidades de saúde familiar, com os seus indicadores e tetos de gastos em meios complementares de diagnóstico e terapêutica (MCDT).

Atualmente, este sistema ainda não teve eco a nível hospitalar. Verificamos no nosso dia-a-dia ainda alguma resistência a um apoio na triagem e escolha dos melhores métodos radiológicos para o esclarecimento das dúvidas diagnósticas levantadas nos pedidos.

O objetivo principal deste estudo foi o de identificar a importância que o radiologista pode assim ter na gestão e triagem dos exames radiológicos, bem como perceber os motivos e quantificar o número de exames que potencialmente são desperdiçados a nível de urgência hospitalar na nossa instituição.

\section{MATERIAL E MÉTODOS}

No seu dia-a-dia de trabalho em urgência hospitalar, das oito às 20 horas, o médico radiologista obtém os pedidos de exame, nomeadamente tomografias computorizadas (TC) e ecografias, através do sistema informático da Radiologia (programa RIS-Glintt ${ }^{\circledR}$ ), englobando os pedidos não só do Serviço de Urgência mas também das diferentes enfermarias das especialidades existentes no nosso centro hospitalar. As radiografias não são por norma relatadas, apenas muito esporadicamente é requisitado relatório, pelo que não foi englobado no nosso estudo. Entre as 20 e as oito horas do dia seguinte, a Urgência de Radiologia é assegurada por uma empresa externa de Telerradiologia, abrangendo unicamente TCs, sem médico presencial na nossa instituição, sem triagem prévia, num modelo baseado no volume.

Definiu-se assim que os exames pedidos com mais de sete dias, ainda não realizados por alguma razão, seriam objeto de análise quanto ao seu motivo de não realização. Os registos médicos eletrónicos seriam consultados para se perceber as causas e o destino final do doente.

Deste modo foram usadas as seguintes causas para cancelamento ou eliminação dos referidos pedidos, previamente existentes no programa RIS-Glintt ${ }^{\circledR}$ :

- 'Alteração do estado do doente': usamos este para englobar doentes que tiveram alta do serviço de Urgência (balcão ou SO), com destino quer a um internamento em enfermaria quer para o exterior, para médico de família, ou para uma consulta externa de especialidade hospitalar. No fundo, englobou-se aqui os exames que demonstraram o carácter pouco ou nada urgente da condição clínica;

- 'Desistência, recusa ou abandono do doente' do nosso serviço de Urgência;

- 'Falecimento do doente';

- 'Sem critério ou contraindicado' nos casos de apoio à triagem efetuado pelo médico radiologista quando este se encontrasse presencial, nomeadamente nos casos em que por exemplo era pedido uma angio-tomografia computorizada e houvesse contraindicação da administração de contraste iodado endovenoso, ou em que a dúvida diagnóstica pudesse ser esclarecida com um novo parecer de exame radiológico prévio recente presente no arquivo digital do nosso centro hospitalar, não havendo necessidade assim de novo exame;

-'Falta de recursos humanos', nas situações apenas e em que o doente tenha sido transferido para outro hospital com o intuito de esclarecer imagiologicamente uma dúvida urgente que não era possível no nosso hospital (p.e. ecografia de madrugada numa situação de torção testicular);

- 'Engano na marcação'.

Foram considerados todos os pedidos assim cancelados segundo os critérios atrás descritos, durante o ano civil de 2015.

Recolheram-se os dados através do programa RIS-Glintt ${ }^{\circledR}$, tendo sido obtidos o número total de exames, sendo que naturalmente um doente poderia ter mais do que um exame (frequentemente é requisitado por exemplo ecografia renal e vesical ou tomografia computorizada abdominal e pélvica, para um mesmo doente).

O presente estudo teve aprovação institucional (Comissão de Ética para a Saúde e Grupo de Investigação e Desenvolvimento).

\section{RESULTADOS}

A Tabela 1 apresenta a distribuição numérica dos exames cancelados da lista de trabalho ao fim de sete dias, e segundo os motivos previamente existentes nas opções de cancelamento.

Verificamos assim que 283 exames foram cancelados após pelo menos sete dias da sua requisição como exame urgente tendo-se verificado alteração do estado do doente. 
Tabela 1 - Distribuição do número de pedidos eliminados no programa RIS-Glintt ${ }^{\circledR}$ segundo o motivo

\begin{tabular}{lc}
\hline Motivo de Cancelamento & Quantidade \\
\hline Alteração do estado do doente & 283 \\
Desistência, recusa ou abandono do doente & 94 \\
Falecimento do doente & 41 \\
Sem critério ou contraindicado & 184 \\
Falta de recursos humanos & 29 \\
Engano na marcação / Repetida & 580 \\
Total & 1211 \\
\hline
\end{tabular}

Através da análise do processo clínico, verificamos que em muitos destes casos o médico requisitante, após a anamnese e exame físico, solicitou exames de patologia clínica e radiológicos, sendo que habitualmente os primeiros são efetuados mais rapidamente e com resultados também mais rápidos e que em muitas destas vezes foram mais do que suficientes na abordagem do doente em urgência hospitalar. Findo o episódio de urgência, o pedido de exame radiológico que assim não era realizado, não era automaticamente cancelado no programa RIS-Glintt ${ }^{\circledR}$ nem o médico requisitante o cancelava, ficando deste modo pendente ou 'esquecido' na lista de trabalho do radiologista.

Por outro lado, em muitas das vezes, era requisitada uma ecografia urgente, desconhecendo o clínico do serviço de Urgência a falha de cobertura na escala de um radiologista àquela hora no hospital. Após tomar conhecimento da falha, verificamos muitas vezes que mesmo assim o doente teve alta quer para o exterior, quer referenciado a uma consulta externa, não chegando a realizar o exame, revelando-se este, deste modo, não imperioso na abordagem do episódio de urgência.

Gastroenterites, síndroma de Gilbert, esteato-hepatites, tumefações cutâneas ou adenomegalias, infeções simples, não complicadas ou típicas do trato urinário em adultos ou crianças predominavam neste lote.

Verificaram-se 94 exames cancelados com um motivo de desistência, recusa ou falta do doente e cerca de 41 exames com motivo de falecido antes do exame. Nestes motivos de cancelamento, observamos que na maioria se verificou um abandono do doente do Serviço de Urgência após algumas horas de espera por atendimento e após tratamento sintomático. Apenas em um doente se verificou que o médico pediu às autoridades policiais para o notificar no domicílio da real necessidade de voltar às Urgências e o perigo em que incorria ao transgredir o aviso.

No caso dos falecidos, o retrato-tipo foi o de um octagenário, com as suas habituais múltiplas comorbilidades, paliativo ou terminal, em estado estuporoso ou agónico final, com pedido de TC de crânio para esclarecimento do quadro neurológico. Na generalidade dos casos, faleceram poucos minutos ou poucas horas após o exame ter sido requisitado.

Foi aplicado 184 vezes o motivo de 'Sem critério ou contraindicado' nos casos de apoio à triagem efetuado pelo médico radiologista, correspondendo a cerca de $15 \%$ do total ou a $31 \%$ do subtotal das quatro primeiras causas da
Tabela 1 (602 exames).

No caso de não haver médico radiologista presencial, uma situação que se verifica em alguns fins-de-semana e durante o período noturno das 20 até às 8 horas da manhã do dia seguinte, e se fosse pedida uma ecografia e não houvesse possibilidade de ser realizada na nossa instituição, tendo o doente que ser transferido para outro hospital, aplicou-se o motivo de falta de recursos humanos, situação em que se verificaram 29 exames cancelados durante o ano civil de 2015, correspondendo a 19 doentes.

Por vezes, observamos situações em que nas mudanças de turno da Urgência se verificava uma correta mudança na prioridade dos pedidos, com ou sem apoio do radiologista. Assim, em situações como estadiamentos tumorais, pesquisa de tumor oculto ou esclarecimento de nódulo pulmonar, foram muitas vezes feitos novos pedidos ou reagendados com prioridade normal, já com o doente internado numa enfermaria, após a alta do SO, tendo no entanto o pedido original ficado pendente.

Foram deste modo cancelados 580 exames por estarem assim repetidos tendo-se usado o motivo 'Engano na marcação' no programa RIS-Glintt ${ }^{\circledR}$ por ser o motivo presente dentro do lote dos possíveis no programa mais parecido com a real causa, embora em senso estrito não se tratasse de um engano mas sim de uma repetição.

Muitas vezes se verificou também que os pedidos estavam repetidos por o clínico ter feito novo pedido algumas horas após o primeiro, logo que o doente tivesse pronta disponibilidade ou por recuperação de estabilidade hemodinâmica. Na prática diária, esta é uma forma alternativa de comunicar à Radiologia que o doente já pode ir agora.

\section{DISCUSSÃO}

Verificamos, assim, um total de 1211 exames cancelados, relativos a exames de ecografia e TCs (quer de Radiologia geral quer de Neurorradiologia), de 1 de janeiro de 2015 a 31 de dezembro do mesmo ano. Estimamos em cerca de 30000 o somatório de ecografias e TCs que são realizados em modo urgente no nosso hospital (não dispomos de dados oficiais).

Se excluirmos os dois últimos motivos da tabela (engano na marcação e falta de recursos humanos), situações em que efetivamente foi feita avaliação imagiológica em modo urgente, embora noutra instituição ou a breve prazo durante o internamento, obtemos um total de 602 exames que não foram pura e simplesmente realizados, nem em 
regime de urgência nem a breve prazo.

Na nossa perspetiva, no bolo total de ecografias e TCs que são realizados em modo urgente no nosso hospital, estarão muitos doentes que realizaram adequada e criteriosamente os exames que se impunham bem como outros que não conseguiram escapar a obstinação diagnóstica ou a certa forma de distanásia como no caso dos doentes do grupo dos falecidos antes do exame.

Estes resultados estão alinhados por um lado com a perceção que temos da realidade atual com a qual contactamos diariamente a nível da nossa urgência hospitalar. Por outro lado há também congruência com o recente Relatório Anual sobre o Acesso a Cuidados de Saúde ${ }^{8}$ onde se estima que $40 \%$ das urgências hospitalares correspondem a falsas urgências e também com o estudo do Observatório Português dos Cuidados Paliativos ${ }^{9}$ onde se refere que cerca de $51 \%$ dos doentes internados nos hospitais são doentes paliativos tendo $16 \%$ destes prognóstico com menos de 15 dias de vida, considerando os médicos, nesse estudo que ainda os podiam curar.

O papel do radiologista como auxiliador na gestão juntamente com o clínico prescritor, numa atitude em equipa, multidisciplinar é a nosso ver a atitude mais correta.

Uma maior adesão a normas de orientação clinica, criando novas e atualizando as pré-existentes no nosso centro hospitalar, englobando recomendações baseadas na evidência (p.e. Appropriateness Criteria [ACR]) e estabelecendo uma forma rápida e fácil de acesso a estas nos sistemas informáticos de uso clínico diário, para além da consulta do parecer do médico radiologista presente na instituição, são formas em que se pode materializar este auxílio. ${ }^{10}$

Uma melhor parametrização do prognóstico do doente, mais formação profissional e acessibilidade dos utentes aos Cuidados Paliativos, associado a mais critério na escoIha de exames imagiológicos que inequivocamente façam a diferença numa atitude terapêutica de urgência poderiam sem dúvida levar a uma melhor otimização deste desperdício.

Por outro lado o estabelecimento de indicadores, perfis ou métrica de gestão, bem como limites ou tetos de gastos para os clínicos hospitalares, tal como já existem para os clínicos dos centros de saúde em modelo USF, tornaria esta aproximação e interação entre o radiologista e o clínico muito mais primordial, diminuindo algumas atitudes de resistência à triagem e de desrespeito pelo parecer do radiologista. Eliminar-se-ia também o conflito de interesse inerente ao modelo baseado no volume de trabalho, com o pagamento por exame quando este é claramente desnecessário ou despropositado.

O nosso estudo teve algumas limitações, nomeadamente alguma variabilidade inter-observador na análise dos registos médicos eletrónicos pelos autores do estudo na busca do motivo da não realização do exame com vista ao seu cancelamento ou eliminação do programa, embora se tenha tentado ao máximo uniformizar os critérios tendo em conta as opções de cancelamento previamente existen- tes no programa e que não puderam ser alteradas pelos autores do estudo.

Por outro lado, apenas tivemos acesso a uma listagem simples do número total de exames, ao passo que a correlação com o número de doentes a que se referiam e a quantidade exata de ecografias ou TCs correspondentes era difícil tendo em conta a complexidade do software usado.

O estudo é relativo a apenas um ano civil e revela uma realidade local de um hospital distrital que pode em certa medida ser diferente de grandes centros com menos médicos tarefeiros ou não especializados e mais médicos com competência em Emergência Médica que o nosso.

Relativamente aos casos de 'Desistência, recusa ou abandono do doente', poderia acontecer que se dirigissem a outro hospital ou se verificasse reingresso alguns dias depois. Em grande parte da eliminação dos exames do programa RIS-Glintt ${ }^{\circledR}$, os autores executaram-na já com bem mais de sete dias de pendência, muitas vezes quase duas semanas, e não verificamos na grande maioria dos casos reingressos no nosso centro hospitalar.

Alguns exames terão sido diretamente cancelados no programa informático dos clínicos da Urgência, diferente do nosso, sem estabelecimento de motivo, o que pode levar a uma subestimativa dos números apresentados.

Serão assim necessários mais estudos para comparação e aferição dos nossos dados.

No entanto, dadas estas condicionantes, o sentimento é o de que os nossos resultados estão em linha com o expressado pela Associação Médica Portuguesa de Radiologistas (AMPR), ao afirmar que a falta de médicos radiologistas em presença nos hospitais do Serviço Nacional de Saúde tem conduzido a uma utilização abusiva de exames com radiação ionizante (nomeadamente TC sob a forma de Telerradiologia).

Muitas vezes estes exames são pouco adequados ao esclarecimento das dúvidas diagnósticas das situações clínicas quando não avaliadas previamente pelo médico radiologista e com os riscos inerentes, ${ }^{11}$ sobretudo em população jovem, estimando-se que esta possa ter um risco acrescido em $24 \%$ na incidência de cancro a longo prazo, ${ }^{12}$ risco este que aumenta a cada TC efetuada.

A aquisição de exames a empresas externas poderá também ser reduzida ou até abolida, se os procedimentos médicos na área da radiologia não constituírem apenas despesa como MCDT's, sem retorno no financiamento hospitalar e com esta medida estimular as administrações hospitalares na contratação de radiologistas.

Num futuro a médio ou longo prazo, vislumbra-se a criação da consulta de Radiologia, valorizando o ato médico do radiologista, havendo já experiências piloto norte-americanas bem sucedidas. ${ }^{13}$

\section{CONCLUSÃO}

Julgamos assim muito importante o papel regulador e até mesmo dissuasor do médico Radiologista, em presença hospitalar. Por um lado evita riscos desnecessários 
para o doente, tais como exames com radiação ionizante, repetições desnecessárias de exame por novo parecer imagiológico de exames prévios, diminuindo ansiedade do doente, redução da espera na execução do exame ao eliminar casos não urgentes ou sem critério que engrossem a lista de espera. Por outro lado reduz gastos, numa melhor triagem e adequação dos exames imagiológicos, em consonância e espírito de multidisciplinaridade e trabalho de equipa com o clínico prescritor.

\section{AGRADECIMENTOS}

Os autores agradecem o contributo na obtenção dos dados e listagens pelo gestor de área Luís Lagartinho do Centro Hospitalar de Setúbal.

\section{PROTEÇÃO DE PESSOAS E ANIMAIS}

Os autores declaram que o presente estudo teve apro-

\section{REFERÊNCIAS}

1. Sarwar A, Boland G, Monks A, Kruskal JB. Metrics for radiologists in the era of value-based health care delivery. RadioGraphics. 2015;35:86676.

2. Rao VM, Levin DC. The overuse of diagnostic imaging and the Choosing Wisely initiative. Ann Intern Med. 2012;157:574-6.

3. Governo de Portugal, Despacho n. 10430/2011 - Diário da República, 2. ${ }^{\text {a }}$ série - N. ${ }^{\circ} 158-18$ de agosto de 2011.

4. Rao VM, Levin DC. The Choosing Wisely initiative of the American Board of Internal Medicine Foundation: what will its impact be on radiology practice? AJR Am J Roentgenol. 2014;202:358-61.

5. Cassel CK, Guest JA. Choosing wisely: helping physicians and patients make smart decisions about their care. JAMA. 2012;307:1801-2.

6. Morden NE, Colla CH, Sequist TD, Rosenthal MB. Choosing wisely - the politics and economics of labeling low-value services. N Engl J Med. 2014;370:589-92.

7. Governo de Portugal. Portaria n. ${ }^{\circ} 377-A / 2013$ - Diário da República, 1. série - N. ${ }^{\circ} 252$ - 30 de dezembro de 2013.

8. Governo de Portugal. Relatório Anual sobre o Acesso a Cuidados de Saúde nos Estabelecimentos do SNS e Entidades Convencionadas (2014). 2015. [consultado 2016 ago 29]. Disponível em: https://www. sns.gov.pt/wp-content/uploads/2016/07/2015-07-20-RA_Acesso_2014- vação institucional (Comissão de Ética para a Saúde e Grupo de Investigação e Desenvolvimento) e se encontra em consonância com a Declaração de Helsínquia da Associação Médica Mundial.

\section{CONFIDENCIALIDADE DOS DADOS}

Os autores declaram ter seguido os protocolos do seu centro de trabalho acerca da publicação de dados.

\section{CONFLITO DE INTERESSES}

Os autores declaram não ter nenhum conflito de interesse relativamente ao presente artigo.

\section{FONTES DE FINANCIAMENTO}

Não existiram fontes externas de financiamento para a realização deste artigo.

VFinal.pdf.

9. Associação Portuguesa de Cuidados Paliativos. Reflexão da Associação Portuguesa de Cuidados Paliativos sobre o Manifesto Morrer com Dignidade. [consultado 2016 ago 29]. Disponível em: http://www.apcp. com.pt/uploads/Manifesto_Pro_Eutanasia_Posicao_da_APCP_vfinal. pdf.

10. Bautista AB, Burgos A, Nickel BJ, Yoon JJ, Tilara AA, Amorosa JK, et al. Do clinicians use the American College of Radiology Appropriateness criteria in the management of their patients? AJR Am J Roentgenol. 2009;192:1581-5.

11. Associação Médica Portuguesa de Radiologistas. Carta ao Ministro da Saúde, 5 de maio de 2015. [consultado 2016 dez 13]. Disponível em: http://bit.ly/2gTfraH.

12. Mathews JD, Forsythe AV, Brady Z, Butler MW, Goergen SK, et al. Cancer risk in 680,000 people exposed to computed tomography scans in childhood or adolescence: data linkage study of 11 million Australians. BMJ. 2013;346:f2360.

13. Mangano MD, Bennett SE, Gunn AJ, Sahani DV, Choy G. Creating a patient-centered radiology practice through the establishment of a diagnostic radiology consultation clinic. AJR Am J Roentgenol. 2015;205:95-9. 